\title{
A school based study of time trends in food habits and their relation to socio-economic status among Norwegian adolescents, 2001-2009
}

\author{
Anne-Siri Fismen ${ }^{1 *}$, Otto Robert Frans Smith ${ }^{1,2}$, Torbjørn Torsheim ${ }^{3}$ and Oddrun Samdal ${ }^{1}$
}

\begin{abstract}
Background: In recent years, adolescents' food habits have become a major source of concern, and substantial policy and intervention efforts have been made to influence adolescents to consume more fruit and vegetables and less sweets and soft drink. Particular attention has been devoted to the social gradient in food habits, aiming to reduce dietary inequality. However, few internationally published studies have evaluated trends in teenagers' food habits, or investigated how dietary inequalities develop.
\end{abstract}

Methods: We used Norwegian cross-sectional data from the international Health Behaviour in School-Aged Children (HBSC) study, collected via three nationally representative and comparable questionnaire surveys in 2001, 2005 and 2009. Food habits were identified by students' consumption of fruit, vegetables, sweets and sugar rich soft drink. Socio-economic status (SES) was measured with the Family Affluence Scale (FAS). Multilevel logistic regression was used to analyze the data.

Results: The analyses indicated an overall positive trend in food habits among adolescents in Norway. Students were more likely to consume fruit (OR 1.76, Cl 1.61-1.92) and vegetables (OR 1.51, Cl 1.37-1.66) daily in 2005 as compared to 2001, and were less likely to consume sweets (OR 0.58, Cl 0.51-0.66 resp. OR 0.77, Cl 0.67-0.90) and soft drink (OR 0.55, Cl 0.49-0.62 resp. OR 0.84, Cl 0.73-0.96) daily when comparing, respectively, 2005 with 2001 and 2009 with 2005. Across all survey years, students with higher SES were more likely to eat fruit (OR 1.47, Cl 1.32-1.65) and vegetables (OR 1.40, Cl 1.24-1.58) daily than did students with lower SES. Our analyses indicated that the socio-economic differences were stable in the period 2002 - 2010, with uniform improvement in fruit and vegetable consumption across all SES levels. No significant associations between SES and intake of sweets and sugar-added soft drink were found.

Conclusion: The study identifies an overall improvement in diet among adolescents over a period characterized by onset of as well as ongoing initiatives targeting young people's food habits. However, the observed socio-economic gradient in fruit and vegetable consumption remained unchanged.

Keywords: Food habits, Fruit, Vegetables, Sweets, Soft drink, Adolescence, Socio-economic inequality, FAS

\section{Background}

Adolescents' food choices and diets have become a major source of concern in recent decades. This must be viewed in the context of western countries' high prevalence of overweight [1-3] and chronic diseases [4-6], and the link to diet [7-10]. Although chronic diseases are not very prevalent among teenagers, there is emerging evidence

\footnotetext{
*Correspondence: Anne-Siri.Fismen@uib.no

'Department of Health Promotion and Development, University of Bergen, Christiesgate 13, Bergen 5015, Norway

Full list of author information is available at the end of the article
}

that there is early onset of risk factors, even in adolescence [11]. Improved food habits among this age group are likely to reduce the population-based incidence of chronic diseases, because food habits established at an early age extend into adulthood [12-14]. Food habits are also highly relevant in terms of social inequalities in health, because dietary inequality is linked to health inequality [15]. This is of particular concern in light of increased recognition that tackling health inequality is a key public health challenge in the twenty-first century. 
Frequent consumption of fruit and vegetables accompanied by a low intake of simple sugar $(<10 \%$ of total energy) is widely recommended by international nutritional authorities [16-18]. However, many schoolchildren fall short of these recommendations [19-24]. Poor diet is of particular concern with regard to adolescents living in families of low socio-economic status (SES), because adolescents of low SES eat less fruit and vegetables [20,25-28] and more sugar-added food items [24,29,30] than their high SES counterparts. Based on this background, initiatives to improve and equalize young people's food habits receive high priority in most Western countries [16,17].

In Norway, improving adolescents' food habits is a national policy goal [31]. Substantial efforts have been made to change the consumption patterns of Norwegian teenagers, who are among the lowest fruit and vegetable consumers in Europe [32] and high consumers of sweetened beverages [33]. Various initiatives, such as information campaigns, school text pamphlets, television and radio announcements and advertisements, have been employed by the national Nutritional Council, often in close collaboration with other organizations and agencies. In order to reach students across all SES groups, several national and regional educational interventions targeting students' food habits have been trialed in Norwegian schools [34-37]. There has been a systematic prioritization of providing fruit and vegetables at schools [38] and in sport halls, and sugar-free mineral water has replaced sugar-added soft drink in vending machines in the vast majority of public schools [34]. Also the grocery industry has been proactive in its marketing of fruit and vegetables, and some grocers reduced the prices of fruit and vegetable by waiving the taxes on fruit and vegetables in 2007, rather than passing them to the consumers. In 2007, a nationwide free (not parent-funded) school fruit program was implemented in all Norwegian secondary schools (grades 8-10) and all combined schools (grades 1-10) in 2007. This is possibly the most comprehensive and costly (230 million NKR/27 million Euro in 2011) initiative targeting Norwegian adolescents' consumption of fruit and vegetables, and it provides all children in lower secondary schools and combined schools with a free piece of fruit or a carrot every day. Marketing of sweets and beverages to young people is strictly prohibited in Norway $[39,40]$ and the government has moreover imposed the world's highest economic fees on soft drink and other non-alcoholic beverages.

Despite all the attention devoted to adolescents' food habits in both Norway and other European countries $[41,42]$, few internationally published studies have evaluated nutrition policies and educational campaigns aimed at teenagers. Moreover, few studies have reported trends in young people's consumption of fruit, vegetables and sugar-rich products such as sweets and soft drinks. The number of studies that report on the development of dietary inequalities is even more limited. Studies of trends in adolescents' food habits are highly relevant for the evaluation of nutrition policies and dietary interventions, as well as for assessing the need for further initiatives aimed at improving and equalizing eating habits. Such studies are of international interest because they provide knowledge about how policies and interventions influence teenagers' food habits. Studies of food habits should moreover measure different items individually. Combining fruit and vegetable intake as a single measurement, for example, does not facilitate assessments of whether consumption is meeting the recommendations for fruit and for vegetables individually. As the determinants of fruit intake and vegetable intake may differ, interventions may be more beneficial if tailored specifically for fruit and for vegetable consumption, separately. Moreover, the effects of SES have been shown to vary among food items $[25,28,43]$. Different food items should therefore be studied individually, in terms of both intake recommendations and socio-economic inequality. Differentiation between specific foods is needed to examine individual trends separately and to follow the social gradient more accurately.

In the present study, we evaluated how trends in the consumption of fruit, vegetables, sweets and soft drink developed among Norwegian adolescents in the period 2001-2009, and how dietary inequalities developed during this period. Building on the systematic strategies and initiatives aimed at improving the food habits and reducing dietary inequalities, improved dietary patterns across all SES groups has been greatly anticipated. We used crosssectional data from the Health Behavior in School-Aged Children (HBSC) study collected via three nationally representative and comparable questionnaire surveys in 2001, 2005 and 2009. The study population consisted of Norwegian schoolchildren aged 11, 13, 15 and 16 years. As far as we know, nationally representative Norwegian data on such trends have never been published internationally.

\section{Methods}

We used data from the Norwegian contribution to the WHO cross-national HBSC study (www.hbsc.org) collected in 2001/2002, 2005/2006 and 2009/2010. A stratified standard cluster sampling procedure was used to ensure national representativeness [44] when selecting the data. School class (classroom unit) was the primary sampling unit, with one participating class per age group in each selected school. A standard cluster sampling procedure based on a geographically stratified list with sequential selection from a randomized starting point was used to select the sample. The overall school, school classes and student response rate was respectively in $73 \%, 88 \%$ and $89 \%$ in survey year 2001 , $69 \%, 69 \%$ and $84 \%$ in survey year 2005 and 55\%, 56\% and $81 \%$ in survey year 2009. Non-responses comprised primarily either class- or school-level, non-participation or 
student absence on the day the survey was administered. Participation was based on passive parental consent. The students answered the questionnaire in the classroom after receiving standardized instructions from their teacher [44]. Participation was anonymous. The students were asked not to write their names on the questionnaire and to return the completed questionnaire in the provided envelope after sealing it. The Privacy Ombudsman at the Norwegian Social Science Services gave assurance that the study complied with Norwegian privacy and confidentiality requirements. The Norwegian Western Regional Ethical Committee determined that the study did not require ethical clearance.

\section{Questionnaire}

The questionnaire was developed through international consensus and translated into the languages of the participating countries. Back-translation to English was approved by independent researchers in the international study [44].

\section{Socio-economic status \\ The Family Affluence Scale (FAS)}

The FAS is a measure of material affluence derived from the characteristics of the family's household. It consists of the following four items: 1. "Does your family own a car, van or truck?" $(\mathrm{No}=0$; One $=1$; Two or more $=2)$. This item is a component of the Scottish Deprivation Index developed by Carstairs and Morris [45], which is used widely in health inequalities research. 2. "How many times have you travelled away on holiday with your family during the past 12 months?" (Never $=0$; Once $=1$; Twice $=2$; Three or more times $=3$ ). This item is a measure of "deprivation of home facilities" [46]. 3. "Do you have a bedroom to yourself?" $(\mathrm{No}=0$; Yes $=1)$. This item is a proxy for overcrowding, classified by Townsend [46] as housing deprivation, and is also a component of the Scottish Deprivation Index. 4. "How many computers does your family own?" (None $=0$; One $=1 ;$ Two $=2$; More than two $=3$ ). This item was introduced into the FAS to better differentiate between SES groups in affluent countries [47]. These FAS items provide a scale that can be easily completed by students [48].

\section{Ridit transformation of FAS}

A central assumption of the present study is that the FAS has at least ordinal measurement properties, and that the scores can be used to rank individuals and groups along a latent continuum of material wealth. When assuming that the ordered categorical variable approximates an underlying, but not measurable, continuous variable, ridit transformation analysis may be used [49]. Ridit transformation converts ordered categorical responses to cumulative probabilities and is a widely used approach for SES scales with ordinal measurement
[50,51]. It has been used in previous HBSC studies [25,52]. In the present study, the FAS was transformed to yield a continuous material deprivation score ranging from 0 to 1 , with a whole-sample mean of 0.5 . The material deprivation score reflects a student's level of family affluence relative to the rest of the cohort. A student with a deprivation score of 1 is at the top of the material hierarchy (100\% of the other students have a lower level of family affluence), whereas a student with a score of 0 is at the bottom of the material hierarchy (no other student has a lower level of family affluence). In the predictive model, with different eating habits as dependent variables, the regression coefficient of the FAS score can be directly interpreted as the predicted difference in eating habits between the least deprived individual and the most deprived individual. This valuable property has been exploited in a series of studies using ordinal SES ratings $[50,51,53]$.

\section{Eating habits}

The levels of consumption of fruit, vegetables, sweets and sweetened soft drink were measured by items with the same wording: "How many times a week do you consume fruit/vegetables/sweets/ sweetened soft drink?" (Never $=0$; Less than once a week $=1$; Once a week $=2$; Two to four times a week $=3$; Five to six times a week $=4$; Once a day $=5$; More than once a day $=6$ ). Students who ate fruit, vegetables, sweets or sugar-added soft drink at least once daily were identified by the responses: "Once a day" and "More than once a day". These responses (categories 4 and 5) were referred to as daily consumption and recoded as 1 . Responses to categories $0-3$ were recoded as 0 .

The aim of the HBSC study is to evaluate health behavior and lifestyle patterns. The outcome variables were dichotomized to measure whether or not the students included fruit and vegetables, as well as sweets and soft drinks, in their everyday diet. The variables have been treated similarly also in other studies [25,28,54] within the HBSC network.

\section{Statistical analysis}

We calculated standardized frequencies of daily consumption of fruit, vegetables, sweets and soft drink for each gender and age group for each year of data collection. Backward difference coding was used to examine the effects of survey year (2005 versus 2001, and 2009 versus 2005). The four measures (daily fruit/vegetables/sweets/ soft drink consumption) were further analyzed separately by multilevel logistic regression models. School class was included as a random effect. Intraclass correlations were derived from the unconditional models and equaled 0.07 , $0.05,0.10$ and 0.13 for respectively daily fruit, vegetables, sweets and soft drink consumption. The results for each outcome were estimated by two models. In model 1 , we 
analyzed the main effects of age, gender, SES and survey year. In model 2, interactions between survey years and gender, age and SES were tested. Estimation of trends was based on analyses of changes in the rates of daily consumption of the four food items calculated for each year. Odds Ratios (ORs) with 95\% confidence intervals (CIs) indicated the likelihood of daily consumption of fruit, vegetables, sweets and soft drink, with certain characteristics relative to the reference group. The reference group for gender was boys. The reference group for age was 11-year-olds.

All statistical analyses were performed in IBM SPSS version 20 .

\section{Results}

\section{Time trends in food habits}

Our analyses indicated an overall positive trend in food habits among adolescents in Norway. Compared with 2001, more students in 2009 reported daily consumption of fruit and vegetables and fewer reported daily consumption of sweets and soft drink.

As shown in Table 1, the improvements in food habits were greatest in the 2001 to 2005 period. Compared with 2001, the number of students reporting daily consumption of fruit and vegetables in 2005 increased by $45 \%$ and 35\%, respectively. However, the analyses identified no further improvements in the 2005 to 2009 period. Students' intake of sweets and soft drink was found to have decreased more consistently, with significant reductions between 2001 and 2005, as well as between 2005 and 2009. The number of students reporting daily consumption of sweets and soft drink decreased by $51 \%$ and $45 \%$, respectively, during the 2001 to 2009 period. The results of the frequency analyses are supported by the multilevel logistic regression analyses presented in Tables 2 and 3, with significant changes in the rates of daily consumption of fruit (OR 1.76, CI 1.61-1.92, $\mathrm{p}<.001)$ and vegetables (OR 1.51, CI 1.37-1.66, p <.001) between 2001 and 2005. Significant changes in the consumption of sweets were found when comparing 2001 with 2005 (OR 0.58, CI 0.51$0.66, \mathrm{p}<.001$ ) and 2005 with 2009 (OR 0.78, CI 0.67-0.90, $\mathrm{p}=.001$ ), and in soft drink consumption between 2001 and 2005 (OR 0.55, CI 0.49-0.62, $\mathrm{p}<.001$ ) and between 2005 and 2009 (OR 0.84, CI 0.73-0.96, $\mathrm{p}=.012$ ).

\section{Socio-economic inequalities}

Analyses of the bivariate associations between SES and food habits indicated a positive association between SES and the consumption of fruit (OR 1.40, CI 1.26-1.56, $\mathrm{p}<.001$ ) and vegetables (OR 1.34, CI 1.20-1.51; $\mathrm{p}<.001$ ); students with higher FAS scores were more likely to eat fruit and vegetables on a daily basis. These associations remained significant after taking into account gender, age, and time (see Table 2). We found no significant association between FAS score and the consumption of sweets and soft drink in the study population. As shown in Tables 2 and 3, the interaction effects between SES and eating habits were not significant, suggesting that the impact of SES on eating habits was stable between 2001 and 2005 and between 2005 and 2009.

\section{Age and gender differences in eating habits}

Age differences were found for the consumption of all four food types. As shown in Tables 3 and 4, older students reported consuming less fruit and vegetables and more sweets and soft drink than younger ones. Girls were more likely to report daily consumption of fruit (OR 1.82, CI1.71-1.94, $\mathrm{p}<.001$ ) and vegetables (OR 1.46, CI 1.36-1.57, $\mathrm{p}<.001$ ) and less likely to report daily consumption of soft drink (OR 0.58, CI 0.53-0.63, $\mathrm{p}<.001)$ than were boys. The observed gender differences increased with for 16 year olds as compared to 11 year olds with regard to fruit (OR 1.34, CI 1.10-1.62, $\mathrm{p}=.003$ ) and vegetable (OR 1.34, CI 1.12-1.62, $\mathrm{p}=.002)$ consumption. The association between age, gender and food habits remained stable over the whole 2001-2009 period except for the consumption of sweets, for which gender differences increased from 2001 to 2005 (OR $=1.27$. CI 1.03$1.56, \mathrm{p}=.024)$ and age differences first increased from 2001 to 2005 and then decreased from 2005 to 2009.

\section{Discussion}

The study identified overall improved food habits during a period in which government and grocery industry initiatives targeting young people's food habits were initiated and ongoing. The analyses indicated that survey year predicted improvements differently for different food items. Although the greatest improvements in all four outcomes were found in the 2001-2005 period, the consumption of

Table 1 Gender- and age-standardized frequencies of food habits by survey year

\begin{tabular}{|c|c|c|c|c|c|c|c|c|c|}
\hline & \multirow{2}{*}{$\begin{array}{l}2001 \\
\%(n)\end{array}$} & \multirow{2}{*}{$\begin{array}{l}2005 \\
\%(n)\end{array}$} & \multirow{2}{*}{$\begin{array}{l}2009 \\
\%(n)\end{array}$} & \multicolumn{3}{|c|}{ Effect of year: 2005 vs 2001} & \multicolumn{3}{|c|}{ Effect of year: 2009 vs 2005} \\
\hline & & & & OR & $95 \% \mathrm{Cl}$ & p-value & OR & $95 \% \mathrm{Cl}$ & p-value \\
\hline Daily fruit & $26.5(1863)$ & $38.5(2477)$ & $37.9(2180)$ & 1.76 & $1.61-1.92$ & $<.001$ & 0.97 & $0.87-1.06$ & .468 \\
\hline Daily vegetables & $20.6(1444)$ & $28.1(1808)$ & $28.3(1630)$ & 1.51 & $1.37-1.66$ & $<.001$ & 1.01 & $0.92-1.11$ & .823 \\
\hline Daily sweets & $16.2(1138)$ & $10.1(649)$ & $7.9(457)$ & 0.58 & $0.51-0.66$ & $<.001$ & 0.77 & $0.67-0.90$ & .001 \\
\hline Daily soft drink & $22.2(1561)$ & $13.8(889)$ & $12.1(697)$ & 0.55 & $0.49-0.62$ & $<.001$ & 0.84 & $0.73-0.96$ & .001 \\
\hline
\end{tabular}

OR - odds ratio; $\mathrm{Cl}$ - confidence interval. 
Table 2 Generalized linear mixed model of daily consumption of fruit and vegetables with fixed effects

\begin{tabular}{|c|c|c|c|c|c|c|c|c|c|c|c|c|}
\hline \multirow[b]{3}{*}{ Fixed effects } & \multicolumn{6}{|c|}{ Daily fruit } & \multicolumn{5}{|c|}{ Daily vegetables } & \multirow[b]{3}{*}{$p$-value } \\
\hline & \multicolumn{3}{|c|}{ Model 1} & \multicolumn{3}{|l|}{ Model 2} & \multicolumn{3}{|c|}{ Model 1} & \multicolumn{2}{|l|}{ Model 2} & \\
\hline & OR & $95 \% \mathrm{Cl}$ & $p$-value & OR & $95 \% \mathrm{Cl}$ & $p$-value & OR & $95 \% \mathrm{Cl}$ & $p$-value & OR & $95 \% \mathrm{Cl}$ & \\
\hline Intercept & 0.47 & $0.43-0.51$ & $<.001$ & 0.48 & $0.44-0.53$ & $<.001$ & 0.32 & $0.29-0.35$ & $<.001$ & 0.32 & $0.29-0.36$ & $<.001$ \\
\hline Female & 1.82 & $1.71-1.94$ & $<.001$ & 1.72 & 1.53-1.95 & $<.001$ & 1.46 & $1.36-1.57$ & $<.001$ & 1.43 & $1.26-1.62$ & $<.001$ \\
\hline Age $=16$ & 0.43 & $0.38-0.47$ & $<.001$ & 0.36 & $0.31-0.42$ & $<.001$ & 0.57 & $0.51-0.64$ & $<.001$ & 0.48 & $0.42-0.56$ & $<.001$ \\
\hline Age $=15$ & 0.62 & $0.56-0.69$ & $<.001$ & 0.59 & $0.52-0.68$ & $<.001$ & 0.67 & $0.61-0.75$ & $<.001$ & 0.67 & $0.57-0.77$ & $<.001$ \\
\hline Age $=13$ & 0.73 & $0.66-0.81$ & $<.001$ & 0.77 & $0.67-0.88$ & $<.001$ & 0.76 & $0.68-0.84$ & $<.001$ & 0.83 & $0.72-0.96$ & .011 \\
\hline 2005 vs 2001 & 1.76 & $1.61-1.92$ & $<.001$ & 1.99 & $1.61-2.46$ & $<.001$ & 1.51 & $1.37-1.66$ & $<.001$ & 1.67 & $1.30-2.15$ & $<.001$ \\
\hline 2009 vs 2005 & 0.97 & $0.89-1.06$ & .486 & 0.89 & $0.72-1.11$ & .312 & 1.01 & $0.92-1.11$ & .793 & 1.00 & $0.78-1.30$ & .977 \\
\hline SES & 1.47 & $1.32-1.65$ & $<.001$ & 1.47 & $1.31-1.64$ & $<.001$ & 1.40 & $1.24-1.58$ & $<.001$ & 1.41 & $1.24-1.60$ & $<.001$ \\
\hline Female $\times$ age $=16$ & & & & 1.34 & $1.10-1.62$ & .003 & & & & 1.34 & $1.12-1.62$ & .002 \\
\hline Female $\times$ age $=15$ & & & & 1.09 & $0.91-1.30$ & .346 & & & & 1.02 & $0.84-1.24$ & .853 \\
\hline Female $\times$ age $=13$ & & & & 0.92 & $0.77-1.10$ & .336 & & & & 0.84 & $0.70-1.01$ & .060 \\
\hline Female $\times 2005 / 2001$ & & & & 0.94 & $0.81-1.10$ & .422 & & & & 0.97 & $0.82-1.15$ & .676 \\
\hline Female $\times 2009 / 2005$ & & & & 1.07 & $0.91-1.25$ & .402 & & & & 0.92 & $0.78-1.08$ & .291 \\
\hline Age $=16 \times 2005 / 2001$ & & & & 0.86 & $0.67-1.10$ & .238 & & & & 0.92 & $0.70-1.21$ & .562 \\
\hline Age $=15 \times 2005 / 2001$ & & & & 0.96 & $0.75-1.22$ & .746 & & & & 1.04 & $0.80-1.36$ & .757 \\
\hline Age $=13 \times 2005 / 2001$ & & & & 0.85 & $0.68-1.08$ & .183 & & & & 0.93 & $0.72-1.22$ & .612 \\
\hline Age $=16 \times 2009 / 2005$ & & & & 0.96 & $0.74-1.24$ & .737 & & & & 1.13 & $0.85-1.48$ & .406 \\
\hline Age $=15 \times 2009 / 2005$ & & & & 1.27 & $0.99-1.61$ & .054 & & & & 1.19 & $0.92-1.53$ & .192 \\
\hline Age $=13 \times 2009 / 2005$ & & & & 1.20 & $0.94-1.52$ & .141 & & & & 1.00 & $0.78-1.29$ & .989 \\
\hline SES $\times 2005 / 2001$ & & & & 0.99 & $0.77-1.27$ & .920 & & & & 0.90 & $0.68-1.18$ & .436 \\
\hline SES $\times 2009 / 2005$ & & & 0.91 & $0.69-1.22$ & .538 & & & & 0.98 & $0.71-1.36$ & .905 & \\
\hline
\end{tabular}

$\mathrm{OR}$ - odds ratio; $\mathrm{Cl}$ - confidence interval; the reference group for gender was boys and for age 11 year olds.

sweets and soft drink decreased steadily, with significant improvements being registered across the entire period. By contrast, no further improvement in fruit and vegetable consumption was found between 2005 and 2009. At all three time points, students from low SES families reported lower intakes of fruit and vegetables than did students from high SES families. The survey year predicted no significant changes in the association between SES and the reporting of daily consumption of fruit and vegetables, suggesting that the socio-economic gradient has remained unchanged since 2001. SES was not a significant determinant for the consumption of sweets and soft drink in any of the years of data collection.

Increased fruit and vegetable consumption has previously been found in regional Norwegian samples in the period 2001-2008 [26,55], as well as in Scotland (2002-2006) [21] and Lithuania (2001-2009) [54], while increased fruit consumption has been found in Denmark (2001-2005) [56] and the Netherlands (2001-2009) [20]. Similarly, reduced intake of sugar-added soft drink has previously been found in a regional Norwegian sample (2001-2008) [29], in Scotland (2002-2006) [21] and the Netherlands (2001-2009) [20]. By contrast, increased consumption of soft drink was found in Lithuania (2001-2009) [54], Ireland (1997-2005) [57] and the USA (1999-2004) [58]. Our findings of age and gender differences are supported by other studies with regard to fruit and vegetables $[21,28,54,56]$ and soft drink [28,29]. The finding that students in high SES groups are more likely to report daily consumption of fruit and vegetables is also supported by other studies [26,28,29]. Stable socioeconomic inequalities in adolescents' fruit and vegetable consumption have also been found in Scotland [21].

Our analysis documents increased fruit and vegetable consumption, and decreased intake of soft drinks and sweets, in the same period as a range of national initiatives aiming to improve food habits was established or maintained. The present study does not evaluate any specific structural incentives or educational interventions and cannot conclude whether the current nutrition policy has had an effect on adolescents' food habits. However, initiatives similar to those characterizing the Norwegian nutrition policy are in the literature evaluated to influence food habits positively. For example, information campaigns like the Norwegian "5 a day" program, as well as nutrition education programs similar 
Table 3 Generalized linear mixed model of daily consumption of sweets and soft drinks with fixed effects

\begin{tabular}{|c|c|c|c|c|c|c|c|c|c|c|c|c|}
\hline \multirow[b]{3}{*}{ Fixed effects } & \multicolumn{6}{|c|}{ Daily sweets } & \multicolumn{5}{|c|}{ Daily soft drink } & \multirow[b]{3}{*}{$p$-value } \\
\hline & \multicolumn{3}{|c|}{ Model 1} & \multicolumn{3}{|c|}{ Model 2} & \multicolumn{3}{|c|}{ Model 1} & \multicolumn{2}{|c|}{ Model 2} & \\
\hline & OR & $95 \% \mathrm{Cl}$ & $p$-value & OR & $95 \% \mathrm{Cl}$ & $p$-value & OR & $95 \% \mathrm{Cl}$ & $p$-value & OR & $95 \% \mathrm{Cl}$ & \\
\hline Intercept & 0.07 & $0.06-0.09$ & $<.001$ & 0.07 & $0.06-0.09$ & $<.001$ & 0.13 & $0.11-0.14$ & $<.001$ & 0.12 & $0.10-0.14$ & $<.001$ \\
\hline Female & 1.03 & $0.94-1.12$ & .564 & 1.15 & $0.92-1.44$ & .229 & 0.58 & $0.53-0.63$ & $<.001$ & 0.61 & $0.50-0.74$ & $<.001$ \\
\hline Age $=16$ & 2.11 & $1.80-2.46$ & $<.001$ & 2.21 & $1.78-2.73$ & $<.001$ & 2.82 & $2.44-3.26$ & $<.001$ & 3.10 & $2.59-3.70$ & $<.001$ \\
\hline $\mathrm{Age}=15$ & 2.02 & $1.72-2.38$ & $<.001$ & 2.30 & $1.84-2.87$ & $<.001$ & 2.53 & $2.18-2.93$ & $<.001$ & 2.57 & $2.14-3.08$ & $<.001$ \\
\hline Age $=13$ & 1.55 & $1.31-1.85$ & $<.001$ & 1.66 & $1.31-2.01$ & $<.001$ & 1.65 & $1.41-1.93$ & $<.001$ & 1.61 & $1.33-1.95$ & $<.001$ \\
\hline 2005 vs 2001 & 0.58 & $0.51-0.66$ & $<.001$ & 0.38 & $0.26-0.54$ & $<.001$ & 0.55 & $0.49-0.62$ & $<.001$ & 0.52 & $0.38-0.72$ & $<.001$ \\
\hline 2009 vs 2005 & 0.78 & $0.67-0.90$ & .001 & 1.36 & $0.87-2.16$ & .167 & 0.84 & $0.73-0.96$ & .012 & 0.92 & $0.63-1.34$ & .667 \\
\hline SES & 0.98 & $0.84-1.16$ & .844 & 0.94 & $0.77-1.15$ & .561 & 0.93 & $0.81-1.07$ & .327 & 0.92 & $0.79-1.07$ & .268 \\
\hline Female $\times$ age $=16$ & & & & 1.01 & $0.77-1.32$ & .971 & & & & 0.83 & $0.65-1.06$ & .137 \\
\hline Female $\times$ age $=15$ & & & & 0.81 & $0.61-1.07$ & .141 & & & & 0.97 & $0.76-1.25$ & .826 \\
\hline Female $\times$ age $=13$ & & & & 0.85 & $0.64-1.12$ & .247 & & & & 1.02 & $0.79-1.33$ & .854 \\
\hline Female $\times$ 2005/2001 & & & & 1.27 & $1.03-1.56$ & .024 & & & & 1.12 & $0.92-1.37$ & .253 \\
\hline Female $\times 2009 / 2005$ & & & & 0.82 & $0.63-1.01$ & .128 & & & & 0.85 & $0.67-1.08$ & .181 \\
\hline Age $=16 \times 2005 / 2001$ & & & & 1.67 & $1.15-2.43$ & .008 & & & & 1.12 & $0.79-1.56$ & .526 \\
\hline Age $=15 \times 2005 / 2001$ & & & & 1.56 & $1.08-2.31$ & .019 & & & & 1.11 & $0.79-1.57$ & .540 \\
\hline Age $=13 \times 2005 / 2001$ & & & & 1.22 & $0.82-1.84$ & .331 & & & & 1.04 & $0.72-1.50$ & .848 \\
\hline Age $=16 \times 2009 / 2005$ & & & & 0.70 & $0.46-1.09$ & .112 & & & & 1.05 & $0.71-1.55$ & .797 \\
\hline Age $=15 \times 2009 / 2005$ & & & & 0.59 & $0.38-0.94$ & .025 & & & & 0.92 & $0.62-1.36$ & .676 \\
\hline Age $=13 \times 2009 / 2005$ & & & & 0.56 & $0.34-0.92$ & .023 & & & & 0.83 & $0.54-1.27$ & .394 \\
\hline SES $\times 2005 / 2001$ & & & & 0.95 & $0.66-1.36$ & .767 & & & & 0.87 & $0.64-1.21$ & .419 \\
\hline SES $\times 2009 / 2005$ & & & & 0.84 & $0.49-1.44$ & .517 & & & & 1.04 & $0.69-1.57$ & .843 \\
\hline
\end{tabular}

OR - odds ratio; $\mathrm{Cl}$ - confidence interval; the reference group for gender was boys and for age 11 year olds.

to those implemented in the Norwegian school, are found to improve food habits [59].

Our findings of improved food habits are encouraging. However, our analysis documented no further improvement in fruit and vegetable consumption when comparing survey year 2009 to 2005 . Given the onset of a nationwide free school fruit program in 2007, and the fact that all students age 13 and 15 in this study cohort was provided with a piece fruit/carrot at school every day, this finding might be surprising. However, this finding indicates that although availability is an important determinant to fruit and vegetable consumption, availability alone is not enough to increase intake of fruit and vegetables. It should also be noted that time trends in fruit and vegetables consumption identified in this study cohort is quite similar to the development in fruit and vegetable intake in Norwegian population as a whole, where fruit consumption increased only slightly between 2003 and 2012, and vegetable consumption increased more steadily [60]. This consumption pattern may have influenced the availability of fruit in the home milieu and may contribute to explain why we found no further increased fruit intake when comparing 2009 to 2005 . The present study does further document an extensive reduction in soft drink consumption. This does probably not reflect a reduction in the total intake of soft drink but rather a replacement of sweetened soft drink by sugar-free alternatives [29] as well as increased use of water on bottles [61].

According to our analyses, socio-economic inequalities in fruit and vegetable consumption remained unchanged in the period were several incentives aiming to reduce dietary inequalities were onset or ongoing. The observed socio-economic gradient might reflect the high cost of fruit and vegetables in Norway. It is shown that purchase of fruit and vegetables is price sensitive $[62,63]$ and that high cost is considered as a barrier to increase the intake in low SES families [64]. Fruit and vegetables are indeed shown to be particularly strongly and consistently associated to socio-economic position in the Northern part of Europe, also over time [65]. With the high cost it might therefore be particularly challenging for lower SES families to respond to the Norwegian authorities' recommendation of providing the whole family with "five a day". However, reducing socioeconomic differences is a national goal in Norway and the politicians held particularly great expectations to the free school fruit program. Our results might 
therefore be disappointing. On the other hand, the uniform improvements in food habits across all SES groups is an encouraging outcome, as improvements in general population health are typically accompanied by increasing inequalities [66,67], with affluent groups achieving health improvements more easily than others. Our findings of no such widening of the inequality gap might indicate that socio-economic circumstances influence adolescents differently to adults, a perspective supported by Hanson and Chen [68], who found dietary inequality to be less robust during adolescence than adulthood.

Intake of sweets and soft drinks was not associated to SES in this study population. This is in line with other studies on adolescents' food habits in western countries $[25,28]$ and moreover in strikingly in contrast to studies on adolescents' soft drink consumption in several Central and Eastern European countries [28,54]. This might, as pointed to by Vereecken [28], indicate that in Central and Eastern European countries, soft drinks are still considered luxury items, affordable only by higher SES groups. However, studies of socio-economic disparities should always be read in the context of the SES indicator that is used. This means that the association between SES and food habits among Norwegian adolescents might be different if the FAS were to be replaced with an indicator that taps other dimensions of the SES construct than material wealth. Soft drink consumption, for example, is associated with SES among Norwegian adolescents in studies that use parental education [29,30,69], parental occupation [28] or cultural capital [25] as indicators of SES. It is likely that soft drinks are less influenced by material wealth as it is relatively cheap compared to other food items in Norway. This emphasizes the complexity of conducting research to identify socio-economic inequality in eating behaviors, in particular among children and adolescents.

\section{Limitations}

The study has limitations that should be considered when interpreting the findings. The use of the FAS could be criticized both methodologically and conceptually. The FAS was developed not to measure material capital among Norwegian adolescents in particular but to investigate the socio-economic circumstances of young people in all of Europe and North America. Computers are currently used in Norwegian school settings and for daily homework. Most teenagers therefore have their own computer. Low automobile ownership might reflect the environmental consciousness of parents rather than low SES. However, the FAS has been shown to be a valid instrument for measuring material circumstances among young people [70,71] and is currently used for this purpose [72]. Moreover, the use of ridit transformation compensates for some of the limitations, making the FAS a relevant SES indicator for Norwegian conditions.

Finally, the HBSC questionnaire has been recognized as a valid instrument in epidemiological studies ranking adolescents according to their usual food intake [73], and is therefore considered valid for measuring the intake of fruit, vegetables, sweets and soft drink. However, it should be noted that the questionnaire only assesses frequency of consumption. When assessing changes over time, changing portion sizes could potentially have influenced our results of dietary habits. Our study does not measure the amount of fruit, vegetable, sweets and soft drinks consumed by the students. The study identifies students' report of frequencies of consumption, and whether the frequencies have changed during 2001-2009.

\section{Implications}

Although the present study demonstrates a positive trend in adolescents' eating patterns, our results underline the need for more comprehensive initiatives targeting young people's food habits. A specific challenge in both Norway and other countries is to increase consumption of vegetables and new approaches might be needed to capture young people's interest vegetables of such food items. Examples of new and interesting initiatives to communicate with teenagers include the Norwegian Ministry of Health's use of social media, such as Facebook and Twitter, to spread knowledge and to encourage them to compete in cooking and the creation of healthy recipes. These initiatives are important in order to make meals rich in fruit and vegetables trendy and popular and should be evaluated.

Moreover, there is a need for more deliberate and focused action to close gaps in social inequalities that affect food choices. Norwegian policy action therefore needs to be strengthened and reoriented from what is now primarily "general" coverage to a focus on the specific needs of low SES groups. One example is the government's suggestion of removing all taxes on fruit, vegetables, which might be particularly relevant to improving food habits among low SES families.

Finally, gender differences in food habits should be taken into account, as school-based interventions aiming to improve health behaviors have been shown to influence boys and girls differently and to favor girls $[69,74,75]$.

Future research should emphasize the need for more systematic evaluation of national policy initiatives, including studies of consumer behavior and the role of structural and educational incentives. Research would also be useful to investigate the effectiveness of the free school fruit scheme, as its continuation is currently under debate by politicians. Moreover, future research should evaluate which factors contribute to social inequalities in food 
habits, as a basis for the future differentiation of interventions among different target groups.

\section{Conclusion}

The present study show that although the majority of Norwegian adolescents are far from meeting the recommendation of including fruit and vegetables in their everyday diet, the trends are moving in a more health-promoting direction, particularly in the period 2001-2005, in which the survey data registered quite an extensive improvement in fruit and vegetable consumption as well as reduces intake of sweets and soft drinks. Improved food habits were found across SES groups and the socioeconomic differences remained unchanged. This is an encouraging outcome, as improvements in general population health are typically accompanied by increasing inequalities. However, we underscore the need for further initiatives that aim to improve young people's food habits and reduce socio-economic disparities in fruit and vegetable consumption. Finally, we emphasize the need for future studies of trends in consumption habits to evaluate how young people's food habits continue to develop.

\section{Abbreviations}

FAS: Family affluence scale; HBSC: Health Behaviour in School-Aged Children; OR: Odds ratio; Cl: Confidence interval; SES: Socio-economic status; WHO: World Health Organization.

\section{Competing interests}

The authors declare that they have no competing interests.

\section{Authors' contributions}

All the authors contributed to the design of the study. RS and ASF analysed the data. ASF drafted the first version of the manuscript. All authors contributed to interpretations of the findings and provided amendments to the text. All authors read and approved the final manuscript.

\section{Acknowledgements}

Health Behavior in School-Aged Children (HBSC) is an international study carried out in collaboration with World Health Organization/Europe WHO/EURO. The International coordinator of the 2001/2002, 2005/2006 and 2009/2010 surveys was Candace Currie, University of Edinburgh, Scotland, and the Data Centre Manager was Oddrun Samdal, University of Bergen, Norway. The Norwegian component of the surveys was chaired by Principal Investigator Oddrun Samdal. For details, see www.hbsc.org.

\section{Author details}

'Department of Health Promotion and Development, University of Bergen, Christiesgate 13, Bergen 5015, Norway. ${ }^{2}$ Division of Mental Health, Norwegian Institute of Public Health, Kalfarveien 31, Bergen 5018, Norway. ${ }^{3}$ Department of Psychosocial Science, University of Bergen, Christiesgate 12, Bergen 5015, Norway.

Received: 24 January 2014 Accepted: 5 September 2014

Published online: 25 September 2014

\section{References}

1. Bibiloni Mdel M, Pons A, Tur JA: Prevalence of overweight and obesity in adolescents:a systematic review. Hindawi Publishing Corporation, ISRN Obes 2013, 2013:392747.

2. Rokholm B, Baker JL, Sørensen TIA: The levelling off of the obesity epidemic since the year 1999 - a review of evidence and perspectives. Obes Rev 2010, 11:835-846.
3. Matthiessen J, Stockmarr A, Biltoft-Jensen A, Fagt S, Zhang H, Groth MV: Trends in overweight and obesity in Danish children and adolescents: 2000-2008 - exploring changes according to parental education. Scand J Public Health 2014, 42:385-392.

4. Song SH: Emerging type 2 diabetes in young adults. Adv Exp Med Biol 2012, 771:51-61.

5. Lobstein T, Frelut ML: Prevalence of overweight among children in Europe. Obes Rev 2003, 4:195-200.

6. Ogden CL, Carroll MD, Curtin LR, McDowell MA, Tabak CJ, Flegal KM: Prevalence of overweight and obesity in the United States, 1999-2004. JAMA 2006, 295:1549-1555.

7. Mosby TT, Cosgrove M, Sarkardei S, Platt KL, Kaina B: Nutrition in adult and childhood cancer: role of carcinogens and anti-carcinogens. Anticancer Res 2012, 32:4171-4192.

8. Steingrimsdottir L, Ovesen L, Moreiras O, Jacob S, Group E: Selection of relevant dietary indicators for health. Eur J Clin Nutr 2002, 56(Suppl 2):8-11.

9. Joshipura KJ, Ascherio A, Manson JE, Stampfer MJ, Rimm EB, Speizer FE, Hennekens $C H$, Spiegelman D, Willett WC: Fruit and vegetable intake in relation to risk of ischemic stroke. JAMA 1999, 282:1233-1239.

10. Key TJ, Allen NE, Spencer EA, Travis RC: The effect of diet on risk of cancer. Lancet 2002, 360:861-868.

11. Currie C, Zanotti C, Morgan A, Currie D, dee Margaretha L, Roberts C, Samdal O, Smith R, Barnekow V, Health Policy for Children and Adolescents $\mathrm{N}$ : Social determinants of health and well-being among young people. Health Behaviour in School-aged Children (HBSC) study: international report from the 2009/2010 survey. In Health Policy for Children and Adolescents. Copenhagen: World Health Organization; 2012.

12. Kelder SH, Perry CL, Klepp KI, Lytle LL: Longitudinal tracking of adolescent smoking, physical activity, and food choice behaviors. Am J Public Health 1994, 84:1121-1126.

13. Lien N, Lytle LA, Klepp KI: Stability in consumption of fruit, vegetables, and sugary foods in a cohort from age 14 to age 21. Prev Med 2001, 33:217-226.

14. Due P, Krølner R, Rasmussen M, Andersen A, Damsgaard MT, Graham H, Holstein BE: Pathways and mechanisms in adolescence contribute to adult health inequalities. Scand J Public Health 2011, 39:62-78.

15. Dowler E: Inequalities in diet and physical activity in Europe. Public Health Nutr 2001, 4:701-709.

16. World Health Organization: Diet, Nutrition and the Prevention of Chronic Diseases, Technical Report Series 916. Geneva: WHO; 2003.

17. Health, Food and Physical Activity. Nordic Plan of Action on Better Health and Quality of Life through Diet and Physical Activity. Copenhagen: The Nordic Council of Ministers for Fisheries and Aquaculture, Agriculture FaFM-FatN, (MR-S) CoMfHaSA; 2004.

18. Nordic Nutrition Recommendations 2012-Integrating Nutrition and Physical Activity, Nord 2014:002. Copenhagen: Nordic Council of Ministers; 2014

19. Andersen LF, Overby N, Lillegaard IT: Hvor mye frukt og grønt spiser norske barn og ungdommer? [Intake of fruit and vegetables among Norwegian children and adolescents]. Tidsskr Nor Laegeforen 2004, 124:1396-1398.

20. Fischer C, Brug J, Tak NI, Yngve A, te Velde SJ: Differences in fruit and vegetable intake and their determinants among 11-year-old schoolchildren between 2003 and 2009. Int J Behav Nutr Phys Act 2011, 8:141.

21. Levin KA, Kirby J, Currie C, Inchley J: Trends in adolescent eating behaviour: a multilevel cross-sectional study of 11-15 year olds in Scotland, 2002-2010. J Public Health (Oxf) 2012, 34:523-531.

22. Overby NC, Lillegaard IT, Johansson L, Andersen LF: High intake of added sugar among Norwegian children and adolescents. Public Health Nutr 2004, 7:285-293.

23. Diethelm K, Jankovic N, Moreno LA, Huybrechts I, De Henauw S, De Vriendt T, Gonzalez-Gross M, Leclercq C, Gottrand F, Gilbert CC, Dallongeville J, Cuenca-Garcia M, Manios Y, Kafatos A, Plada M, Kersting M, HELENA Study Group: Food intake of European adolescents in the light of different food-based dietary guidelines: results of the HELENA (Healthy Lifestyle in Europe by Nutrition in Adolescence) Study. Public Health Nutr 2012, 15:386-398.

24. Duffey KJ, Huybrechts I, Mouratidou T, Libuda L, Kersting M, De Vriendt T, Gottrand F, Widhalm K, Dallongeville J, Hallstrom L, Gonzalez-Gross M, De Henauw S, Moreno LA, Popkin BM, HELENA Study group: Beverage consumption among European adolescents in the HELENA study. Eur $J$ Clin Nutr 2012, 66:244-252. 
25. Fismen AS, Samdal O, Torsheim T: Family affluence and cultural capital as indicators of social inequalities in adolescent's eating behaviours: a population-based survey. BMC Public Health 2012, 12:1036.

26. Hilsen M, van Stralen MM, Klepp Kl, Bere E: Changes in 10-12 year old's fruit and vegetable intake in Norway from 2001 to 2008 in relation to gender and socioeconomic status - a comparison of two cross-sectional groups. Int J Behav Nutr Phys Act 2011, 8:108.

27. Rasmussen M, Krolner R, Klepp Kl, Lytle L, Brug J, Bere E, Due P: Determinants of fruit and vegetable consumption among children and adolescents: a review of the literature. Part I: Quantitative studies. Int J Behav Nutr Phys Act 2006, 3:22.

28. Vereecken CA, Inchley J, Subramanian SV, Hublet A, Maes L: The relative influence of individual and contextual socio-economic status on consumption of fruit and soft drinks among adolescents in Europe. Eur J Public Health 2005, 15:224-232.

29. Stea TH, Overby NC, Klepp Kl, Bere E: Changes in beverage consumption in Norwegian children from 2001 to 2008. Public Health Nutr 2012, 15:379-385

30. Totland TH, Lien N, Bergh IH, Bjelland M, Gebremariam MK, Klepp Kl, Andersen LF: The relationship between parental education and adolescents' soft drink intake from the age of 11-13 years, and possible mediating effects of availability and accessibility. Br J Nutr 2013, 110:1-8.

31. Directorate of Health: Anbefalinger for kosthold, ernæring og fysisk aktivitet (Recommendations for eating habits, nutrition and pysical activity). Report IS-2170. Oslo: Helsedirektorate; 2011.

32. Yngve A, Wolf A, Poortvliet E, Elmadfa I, Brug J, Ehrenblad B, Franchini B, Haraldsdottir J, Krolner R, Maes L, Pères-Rodrigo C, Sjostrom M, Thòrsdòttir I, Klepp Kl: Fruit and vegetable intake in a sample of 11-year-old children in 9 European countries: The Pro Children Cross-sectional Survey. Ann Nutr Metab 2005, 49:236-245.

33. Directorate of Health: Ungkost 2000 - Landsomfattende kostholdsundersøkelse blant elever i 4. og 8. klasse i Norge. IS 1019. Oslo: Sosial og helsedirektoratet; 2002.

34. Holthe A, Larsen T, Samdal O: Understanding barriers to implementing the Norwegian national guidelines for healthy school meals: a case study involving three secondary schools. Matern Child Nutr 2011, 7:315-327.

35. Aadland A, Haug G, Rimestad A, Samdal O: Norway: physical activity and healthy eating in school. In Addressing the Socioeconomic Determinants of Healthy Eating Habits and Physical Activity Levels among Adolescents. Copenhagen: World Health Organization; 2006.

36. Larsen T, Samdal O, Tjomsland H: Physical activity in schools. A qualitative case study of eight Norwegian schools' experiences with the implementation of a national policy. Health Educ 2013, 113:52-63.

37. Aadland A, Haug G, Rimestad A, Samdal O: Norway: physical activity and healthy eating in school. In Addressing the Socioeconomic Determinants of Healthy Eating Habits and Physical Activity Levels among Adolescents. Copenhagen: Organization WH; 2006:59-65.

38. Retningslinger for skolemåltidet (Guidelines for school meals). http://www.helsedirektoratet.no/publikasjoner/retningslinjer-for-skolemaltidet Sider/default.aspx.

39. The Norwegian Directorate of Health's: Annual Report on Measures to Reduce Social Inequalities in Health. Oslo: Directorate of health; 2009.

40. Retningslinjer for markedsføring av mat og drikke rettet mot barn og unge Guidelines for Marketing Food and Beverages for Yong People. Oslo: The Nordic Council of Ministers; 2007.

41. Samdal O: Actions to equalize social and health opportunities in Norway through schools. In Improving the Lives of Children and Young People: Case Studies from Europe. Edited by Barnekow V, Jensen BB, Currie C, Dyson A, Eisenstadt N, Melhuish E. Copenhagen: World Health Organisation; 2013:76-83.

42. World Helath Organization: Adressing the Socioeconomic Determinants of Healthy Eating Habits and Psysical Activity Levels among Adolescents. Copenhagen: WHO/HBSC FORUM 2006; 2006.

43. Iversen AC, Holsen I: Inequality in Health, Psychosocial Resources and Health Behavior in Early Adolescence: The Influence of Different Indicators of Socioeconomic Position. Child Indic Res 2008, 1:291-302.

44. Roberts C, Freeman J, Samdal O, Schnohr CW, de Looze ME, Nic Gabhainn S, lannotti R, Rasmussen M: The Health Behaviour in School-aged Children (HBSC) study: methodological developments and current tensions. Int J Public Health 2009, 54(Suppl 2):140-150.

45. Carstairs V, Morris R: Deprivation and health in Scotland. Health Bull 1990, 48:162-175
46. Townsend P: Deprivation. J Soc Policy 1987, 16:125-146.

47. Schnohr C, Kreiner S, Due EP, Currie C, Boyce W, Diderichsen F: Differential Item Functioning of a Family Affluence Scale: Validation Study on Data from HBSC 2001/02. Soc Indic Res 2008, 89:79-95.

48. Currie CMM, Boyce W, Holstein B, Torsheim T, Richter M: Researching health inequalities in adolescents: the development of the Health Behaviour in School-Aged Children (HBSC) family affluence scale. Soc Sci Med 2008, 66:1429-1436.

49. Bross IDJ: How to use ridit analysis. Biometrics 1958, 3:189-209.

50. Mackenbach JP, Kunst AE: Measuring the magnitude of socio-economic inequalities in health: an overview of available measures illustrated with two examples from Europe. Soc Sci Med 1997, 44:757-771.

51. Manor O, Matthews S, Power C: Comparing measures of health inequality. Soc Sci Med 1997, 45:761-771.

52. Torsheim T, Currie C, Boyce W, Kalnins I, Overpeck M, Haugland S: Material deprivation and self-rated health: a multilevel study of adolescents from 22 European and North American countries. Soc Sci Med 2004, 59:1-12.

53. Cavelaars AE, Kunst AE, Geurts JJ, Helmert U, Lundberg O, Mielck A, Matheson J, Mizrahi A, Rasmussen N, Spuhler T, Mackenbach JP: Morbidity differences by occupational class among men in seven European countries: an application of the Erikson-Goldthorpe social class scheme. Int J Epidemiol 1998, 27:222-230.

54. Zaborskis A, Lagunaite R, Busha R, Lubiene J: Trend in eating habits among Lithuanian school-aged children in context of social inequality: three cross-sectional surveys 2002, 2006 and 2010. BMC Public Health 2012, 12:52.

55. Kvaavik E, Samdal O, Trygg K, Johansson L, Klepp Kl: Fem om dagen - ti år etter (five a day - ten years later). Tidsskr Nor Laegeforen 2007, 127:2250-2253.

56. Rasmussen M, Krolner R, Svastisalee CM, Due P, Holstein BE: Secular trends in fruit intake among Danish schoolchildren, 1988 to 2006: changing habits or methodological artefacts? Int J Behav Nutr Phys Act 2008, 5:6.

57. Kerr MA, Rennie KL, McCaffrey TA, Wallace JM, Hannon-Fletcher MP, Livingstone $M B$ : Snacking patterns among adolescents: a comparison of type, frequency and portion size between Britain in 1997 and Northern Ireland in 2005. Br J Nutr 2009, 101:122-131.

58. Bleich SN, Wang YC, Wang Y, Gortmaker SL: Increasing consumption of sugar-sweetened beverages among US adults: 1988-1994 to 1999-2004. Am J Clin Nutr 2009, 89:372-381.

59. Brambila-Macias J, Shankar B, Capacci S, Mazzocchi M, Perez-Cueto FJ, Verbeke W, Traill WB: Policy interventions to promote healthy eating: a review of what works, what does not, and what is promising. Food Nutr Bull 2011, 32:365-375.

60. grønt Offo: Totaloversikten 2003-2012. Frisk frukt, bær, grønnsaker og poteter. 2013.

61. Bugge AB: Spis deg sunn, sterk, slank,skjønn, smart, sexy... - finnes en diett for alt?. (Eat-your selves healthy, slim, beautiful, samrt, sexy.... Is there a diet for everything?). Oslo: Statens institutt for Forbruksforskning SIFO, rapport nr 4; 2012.

62. Waterlander WE, de Boer MR, Schuit AJ, Seidell JC, Steenhuis IH: Price discounts significantly enhance fruit and vegetable purchases when combined with nutrition education: a randomized controlled supermarket trial. Am J Clin Nutr 2013, 97:886-895.

63. Waterlander WE, Steenhuis $H$, de Boer MR, Schuit AJ, Seidell JC: The effects of a $25 \%$ discount on fruits and vegetables: results of a randomized trial in a three-dimensional web-based supermarket. Int J Behav Nutr Phys Act 2012, 9:11.

64. Drewnowski ADN, Briend A: Replacing fats and sweets with vegetables and fruits-a question of cost. Am J Public Health 2004, 94:1555-1559.

65. Roos GPR: Disparities in Food Habits. Review of Research in 15 European Countries. Helsinki: Institute. F-DGtaRHNPH; 1999.

66. Bronnum-Hansen $\mathrm{H}$, Baadsgaard M: Increase in social inequality in health expectancy in Denmark. Scand J Public Health 2008, 36:44-51.

67. Næss $\varnothing$, Rognerud M, Strand BH: Sosial ulikhet i helse. En faktarapport. vol. 1. Oslo: Folkehelseinstituttet; 2007

68. Hanson M, Chen E: Socioeconomic Status and Health Behaviors in Adolescence: A Review of the Literature. J Behav Med 2007, 30:263-285.

69. Bjelland M, Bergh IH, Grydeland M, Klepp Kl, Andersen LF, Anderssen SA, Ommundsen Y, Lien N: Changes in adolescents' intake of sugar-sweetened beverages and sedentary behaviour: results at 8 month mid-way assessment of the HEIA study-a comprehensive, multi-component school-based randomized trial. Int J Behav Nutr Phys Act 2011, 8:63.

70. Boudreau B, Poulin C: An Examination of the Validity of the Family Affluence Scale II (FAS II) in a General Adolescent Population of Canada. Soc Indic Res 2009, 94:29-42. 
71. Boyce $W$, Torsheim $T$, Currie C, Zambon A: The family affluence scale as a measure of national wealth: validation of an adolescent self-report measure. Soc Indic Res 2006, 78:473-487.

72. Currie CZC, Morgan A, Currie D, de Looze M, Roberts C, Samdal O, Smith ORF, Barnekow V: Social determinants of health and well-being aming young people: Health Behaviour in School-Aged Children (HBSC) study: international report from the 2009/2010 survey. In Health Policies for Children and Adolescents. Copenhagen: WHO; 2012

73. Vereecken $C A$, Maes $L$ : A Belgian study on the reliability and relative validity of the Health Behaviour in School-Aged Children food-frequency questionnaire. Public Health Nutr 2003, 6:581-588.

74. Grydeland $\mathrm{M}$, Bjelland $\mathrm{M}$, Anderssen $\mathrm{SA}$, Klepp Kl, Bergh $\mathrm{H}$, Andersen $\mathrm{LF}$, Ommundsen $Y$, Lien N: Effects of a 20-month cluster randomised controlled school-based intervention trial on BMI of school-aged boys and girls: the HEIA study. Br J Sports Med 2014, 48(9):768-773.

75. Grydeland M, Bergh $\mathbb{H}$, Bjelland M, Lien N, Andersen LF, Ommundsen $Y$, Klepp Kl, Anderssen SA: Intervention effects on physical activity: the HEIA study - a cluster randomized controlled trial. Int I Behav Nutr Phys Act 2013, 10:17. http://www.ijbnpa.org/content/10/1/17.

doi:10.1186/s12966-014-0115-y

Cite this article as: Fismen et al:: A school based study of time trends in food habits and their relation to socio-economic status among Norwegian adolescents, 2001-2009. International Journal of Behavioral Nutrition and Physical Activity 2014 11:115.

\section{Submit your next manuscript to BioMed Central and take full advantage of:}

- Convenient online submission

- Thorough peer review

- No space constraints or color figure charges

- Immediate publication on acceptance

- Inclusion in PubMed, CAS, Scopus and Google Scholar

- Research which is freely available for redistribution 